\title{
Treino didático de análise de contingências e previsão de intervenções sobre as consequências do responder
}

\section{Didactic training of contingency analysis and prediction of interventions on the consequences of responding}

\section{Giovana Del Prette ${ }^{1}$}

[1] Núcleo Paradigma de Análise do Comportamento e Universidade de São Paulo (USP), Brasil | Título abreviado: Análise e intervenção: O controle pelas consequências | Endereço para correspondência: Giovana Del Prette. Rua Wanderley, 611. CEP: 05013-000. São Paulo, SP. |E-mail: gdprette@gmail.com

Resumo: O objetivo deste artigo é ensinar o passo a passo da construção de quadros de tríplice contingência, a partir da elaboração de hipóteses funcionais a respeito das relações entre respostas, seus antecedentes e suas consequências. O texto contém diversas perguntas grifadas, sinalizando que o leitor deve respondê-las antes de prosseguir. Inicialmente, a partir de exemplos simples, são discutidas as questões necessárias à elaboração de análises de contingências e, aos poucos, são colocados exemplos mais complexos. Estes requerem a compreensão de que, em situações não controladas, as respostas usualmente produzem múltiplas consequências, sobrepondo ou alternando reforçamento, punição e extinção. Em uma segunda etapa, apresenta-se também um exercício de previsão dos efeitos de intervenções sobre as consequências do responder. São enfocadas a modelagem e o reforçamento diferencial a partir do relato do cliente e dos seus comportamentos na própria interação terapêutica. Ressaltando a importância do reforçamento natural, o trabalho se encerra com a apresentação das prováveis mudanças do cliente no exemplo hipotético, a partir das intervenções levantadas.

Palavras-chave: análise de contingências, hipótese funcional, intervenção, modelagem, reforçamento natural

\begin{abstract}
The aim of this article is to teach how to develop triple contingencies tables, based on functional hypotheses about the relationships between responses, its antecedents and consequences. The text has a number of highlighted questions that should be answered by the reader. Beginning with simple examples, the issues necessary for the development of contingency analysis are discussed and gradually more complex examples are presented. The last requires an understanding that, in uncontrollable situations, responses usually produce multiple effects, overlapping or alternating reinforcement, punishment and extinction. Afterwards, an exercise about predicting the effects of interventions over the consequences of responding is presented. Focus on modeling and differential reinforcement, based on the client's relates and his behavior in the very therapeutic interaction, are provided. Emphasizing the importance of natural reinforcement, the work is concluded presenting the likely changes of the client in the hypothetical example, based on the interventions gathered.
\end{abstract}

Keywords: contingency analysis, functional hypothesis, intervention, modeling, natural reinforcement 
O objetivo deste artigo é ensinar ao analista do comportamento em formação, de modo didático, a construir quadros de tríplice contingência, coletando de forma precisa e suficiente as informações necessárias e elaborando hipóteses funcionais a respeito das relações entre respostas, seus antecedentes e suas consequências. A partir de exemplos simples, o texto pretende conduzir o leitor a formular contingências cada vez mais complexas, especialmente no campo das consequências. Este, como se sabe, em situações não controladas experimentalmente, costuma incluir diferentes esquemas de reforçamento, com componentes de extinção, punição, reforços positivo e negativo, que se sobrepõem e formam a singularidade da ontogenia de cada ser humano. Em uma segunda etapa, apresenta-se também um exercício de previsão de intervenções sobre as consequências do responder, com foco na modelagem e no reforçamento diferencial a partir do relato do cliente e dos seus comportamentos na própria interação terapêutica.

Ao longo do texto, são formuladas perguntas ao leitor (destacadas em itálico), com o intuito de que ele mesmo elabore suas respostas (pensando, discutindo com colegas ou escrevendo em folha à parte) antes de dar continuidade à leitura. Assim, a organização deste material pretende, adicionalmente, favorecer um treino das habilidades de raciocínio do analista em formação, condizente com os pressupostos teóricos brevemente explicitados a seguir.

Somos terapeutas analítico-comportamentais à medida que temos uma prática profissional clínica guiada por uma filosofia denominada behaviorismo radical e pela ciência da análise do comportamento (Meyer, Del Prette, Zamignani, Banaco, Neno \& Tourinho, 2010; Sturmey, 1996). Dessa afirmativa, deriva-se muito do que precisamos saber e aprender para a nossa formação enquanto profissionais.

Enquanto prática profissional clínica, queremos especificar um campo que possui certas características e para o qual o terapeuta analítico-comportamental possui as ferramentas necessárias. A clínica, portanto, delimita uma das diversas possibilidades de prestação de serviços, como a escola (Psicologia Escolar), o hospital (Psicologia Hospitalar), as empresas (Psicologia Organizacional) e assim por diante. A clínica também especifica um setting - culturalmente determinado - que ocorre por meio de uma interação face a face, individual e de gabinete, embora tenha suas variações, como o acompanhamento terapêutico e a terapia em grupo. Essa interação especial é composta de um indivíduo (o paciente) que procura ajuda para um problema e outro (o terapeuta) que deve prover condições para aliviar seu sofrimento e melhorar seu funcionamento cotidiano (Garfield, 1980). Além disso, embora haja variações no método e na interpretação dos fenômenos psicológicos, os objetivos da clínica são, em geral, alcançados primariamente por meio de contato interpessoal, via interação verbal entre terapeuta e cliente (Kazdin, 1988; Kazdin \& Weisz, 2003).

Posto isso, entende-se que esta prática se ampara em um modo de compreender o mundo - a filosofia do behaviorismo radical - e em um corpo de conhecimentos cientificamente produzidos - a análise do comportamento -, coerente com esta filosofia (a esse respeito, ver, por exemplo, Carrara [2005] e Tourinho [1999]). Segundo Lattal (2005), um dos objetivos da análise do comportamento, enquanto ciência, é "desenvolver princípios comportamentais gerais que podem ser aplicados igualmente a humanos e a não humanos" (p. 16). Tais conhecimentos são produzidos por meio de pesquisas básica e aplicada. Na pesquisa básica, os comportamentos do pesquisador estão sob controle da produção final de novos conhecimentos e do desenvolvimento de métodos e técnicas para análise, previsão e controle do comportamento. Na pesquisa aplicada, o pesquisador também se comporta sob controle da produção de conhecimento, mas com um foco mais direto em questões práticas.

Um dos resultados das primeiras pesquisas básicas, conduzidas por Skinner e sua equipe de pesquisadores, foi a constatação de relações entre as respostas dos organismos e suas consequências (e.g., Sidman, 2001; Skinner, 1938). Estas pesquisas são ditas empíricas. O empirismo se refere à utilização de métodos científicos tradicionais (aqueles originários do empirismo filosófico), de modo que as teorias científicas produzidas se baseiam na observação do mundo, e não na intuição ou na fé. Em outras palavras, a relação entre respostas e suas consequências é oriunda de observação sistemática (com controle de variáveis), de modo que esta relação é um fato, e não uma suposição ou elaboração. Consequências de uma resposta operante 
retroagem sobre ela, aumentando ou diminuindo a sua probabilidade, o que caracteriza o comportamento operante. O comportamento operante é didaticamente descrito em termos de uma tríplice contingência, composta de antecedentes (estímulos discriminativos e operações estabelecedoras, quando houver), respostas e consequências.

Dos muitos atributos do comportamento operante dos organismos, alguns são de especial interesse neste artigo, a saber:

- A capacidade das respostas serem afetadas pelas consequências é determinada filogeneticamente.

- As relações específicas que são estabelecidas entre resposta e consequência são determinadas ontogeneticamente.

Tais relações podem ser classificadas como reforçamento (positivo ou negativo), punição (positiva ou negativa) e extinção operante.

O empirismo não apenas especifica o método de produção do conhecimento, como também uma posição filosófica, segundo a qual este conhecimento vem do mundo observável, e não das ideias (ou mente, consciência, psiquê, alma e afins). Este aspecto é, pois, coerente com outros atributos do behaviorismo radical, como o monismo (em oposição ao dualismo mente-corpo). Sendo assim, na clínica, o método de coleta de dados do analista (prestador de serviços) também deve ser, primordialmente, a observação do comportamento, organizado sob a forma esquemática da tríplice contingência. Usualmente, interações são compostas de longas cadeias de respostas, em que a resposta de um indivíduo é antecedente ou consequência para a do outro. Para fins de análise (decomposição em fatores), a tríplice contingência corresponde a um recorte da menor unidade funcional dessas cadeias.

O treino de observação deve fazer parte da formação do terapeuta analítico-comportamental. Ele inclui algumas habilidades, a começar pela habilidade de selecionar um comportamento-alvo (incluindo respostas e estímulos) e de descrever acuradamente este comportamento. $\mathrm{O}$ analista em treinamento pode iniciar este treino a partir de comportamentos simples, de organismos humanos ou não, conforme será apresentado a seguir.

\section{Análise de Contingências}

Pense como você selecionaria e descreveria os comportamentos a seguir:

- Um gato em uma caixa experimental, puxando uma corda com sua pata.

- Um bebê chorando porque "gosta de fazer manha”.

- Um menino birrento de sete anos, com autoestima baixa.

Perceba que os exemplos acima não necessariamente incluem todos os termos da tríplice contingência, nem mesmo estão descritos da melhor maneira para que o terapeuta em formação possa prosseguir em sua análise. Foram assim colocados de modo proposital, pois muitas vezes, devido ao repertório (ainda incipiente) de descrição de eventos, os clientes podem trazer também informações incompletas, análogas a estes exemplos. Nesses casos, o terapeuta tem duas opções básicas, atuando simultaneamente sobre ambas na maior parte das vezes. A primeira é preencher as "lacunas" da tríplice contingência com hipóteses funcionais. Para isso, pode lançar mão de tantas hipóteses quantas forem necessárias e plausíveis, levando em conta todas as informações de que dispuser. A segunda, complementar, é organizar-se para coletar, de algum modo, as informações omissas - o que o leva a fortalecer ou a refutar algumas das hipóteses já aventadas, a criar novas hipóteses ou a complexificá-las. Vamos verificar como isso se dá a partir do primeiro exemplo, mais simples: "Um gato em uma gaiola experimental, puxando uma corda com sua pata". Qual seria a organização didática desta informação?

Observe:

\begin{tabular}{lll}
\hline Antecedente & Resposta & Consequência \\
\hline Gaiola experimental & Puxar uma & $?$ \\
Presença de uma corda & corda & \\
\hline
\end{tabular}

No campo da resposta, preenchemos a ação do gato, puxar uma corda. Sabemos também onde o gato se encontra, um contexto mais amplo ou a gaiola experimental, descrita em termos de antecedente, em que também acrescentamos outros estímulos relevantes, ou o contexto mais específico, a presença de uma corda que possa ser puxada. Note que, muitas vezes, não é necessário que o antecedente seja algo 
"acontecendo" no mundo, mas somente algo "presente" no mundo. Lembrar-se disso facilita a identificação das informações necessárias para este campo.

Quanto às consequências, não temos qualquer informação a preencher (isto é muito comum; clientes raramente descrevem as consequências de comportamentos ${ }^{1}$ !). Então lançamos mão de hipóteses. Uma vez que puxar uma corda dificilmente seria um comportamento respondente, nossa primeira pergunta pode ser: o que mantém a resposta? Será um reforço positivo (o gato ganha algo) ou negativo (o gato elimina algo)? Em seguida, podemos observar o gato ou perguntar ao experimentador (e confiar na precisão de seu relato). Talvez notemos que puxar a corda não acrescenta nada ao ambiente do gato que possa ser detectável pelo observador, mas não puxá-la sistematicamente leva à ocorrência de um choque pelas grades do chão da gaiola. Como você operacionalizaria esta contingência, agora completa?

Veja:

\begin{tabular}{lll}
\hline Antecedente & Resposta & Consequência \\
\hline $\begin{array}{l}\text { Gaiola experimental } \\
\begin{array}{l}\text { Presença de uma } \\
\text { corda }\end{array}\end{array}$ & $\begin{array}{l}\text { Puxar a corda } \\
\text { com a pata }\end{array}$ & $\begin{array}{l}\text { Pospor choque } \\
\left(\mathrm{Sr}_{\mathrm{r}}\right)^{1}\end{array}$ \\
\hline
\end{tabular}

Agora temos uma contingência razoavelmente completa, em uma situação experimental simples. Em resumo, buscamos características do contexto (antecedente), verbos indicativos das ações do sujeito (resposta) e alterações ambientais resultantes de tais ações (consequência), especificando sua função (no caso, Sr=, retirada de estímulo reforçador negativo). Como você descreveria o quadro acima?

\section{Observe:}

Em uma gaiola experimental, a presença de uma corda é ocasião para que o gato puxe esta corda com a pata e, como consequência, posponha um choque $(\mathrm{S} \mathrm{r}-)$, programado experimentalmente para ser liberado a cada $x$ intervalo de tempo e adiado por meio desta resposta.

Exemplos de reforçamento negativo do tipo esquiva podem parecer mais difíceis de serem analisados, uma vez que não se observa a ocorrência da estimulação aversiva. O exemplo aqui apresentado

1 Nossa cultura costuma referir sentimentos como causa dos comportamentos e um dos efeitos desta prática é o obscurecimento dos termos ambientais da contingência. se assemelha à "esquiva sem sinais de aviso", descrita por Sidman (2001):

Uma vez que tenham aprendido [a pospor choques], eles pressionam a barra com frequência suficiente para receber choques apenas ocasionalmente. Macacos ficarão dias sem um choque, raramente diminuindo o suficiente a velocidade para receber um lembrete da contingência. Eles comportam-se com uma persistência e uma compulsividade que se assemelha ao comportamento patologicamente rígido e inflexível que frequentemente vemos ao nosso redor - algumas vezes em pessoas que, quanto ao resto, são normais. Com esquiva não sinalizada, o que o sujeito faz parece completamente não relacionado a qualquer coisa mais. (pp. 144-145)

Passemos ao segundo exemplo, ligeiramente mais complexo - "Um bebê chorando porque 'gosta de fazer manha"' -, outra descrição não apenas incompleta, mas com atribuições causais mentalistas: diz-se que o bebê chora porque gosta de fazer manha e que faz manha quando está chorando; neste círculo vicioso, perdemos de vista as variáveis ambientais. Além de ser uma explicação equivocada, pode levar o analista pouco experiente a supor que "gostar de fazer manha" seria uma consequência do chorar. Com estas poucas informações, como poderíamos preencher corretamente o quadro da tríplice contingência?

Observe:

\begin{tabular}{|lll|}
\hline Antecedente & Resposta & Consequência \\
\hline$?$ & $\begin{array}{l}\text { Bebê chorando } \\
\text { ("manha") }\end{array}$ \\
\hline
\end{tabular}

Note que toda a frase só indica a resposta do bebê. A manha, aqui, não passa de uma maneira alternativa (e ainda menos descritiva) de se afirmar que o bebê chora. Precisamos nos perguntar a respeito do antecedente, ou seja: quando e em que contextos o bebê chora? Neste caso, temos uma pista, derivada de algumas características socialmente atribuídas à palavra manha: este termo é usualmente referido a certas ações que produzem impacto sobre outra pessoa de um modo específico. Não se pode fazer manha para ninguém ver; isso não seria manha, mas alguma outra coisa. Logo, pode-se supor a presença de alguém no contexto em que 
essa resposta ocorre. Perguntamos aos cuidadores: "Para quem o bebê faz manha?" Assim, obtemos a resposta de que precisávamos. Mas ainda não é uma garantia de que esta verbalização esteja bem formulada, como em: "Ah, ele faz manha para todo mundo". Essa descrição dos pais sobre o comportamento do bebê pode ser uma regra ${ }^{2}$ correspondente, se a manha é bastante generalizada. No entanto, é (mais provavelmente) não correspondente, se os cuidadores não são bons observadores (no caso, a generalização é deles) ou se eles não têm acesso a todas as interações possíveis do bebê para chegarem a esta conclusão categórica. Como você testaria a veracidade do dado de que o bebê faz manha "para todo mundo"? Que perguntas poderiam ser feitas aos pais?

Seguem algumas opções:

- O bebê faz mais manha com algum dos pais? (Funções da pergunta: (a) obter dados e, pela comparação, (b) alterar a descrição de que as manhas são iguais e indiscriminadas.)

- Com quem o bebê passa os dias, além dos pais (e.g., babá, educadora, tios e avós)? Por quanto tempo os pais já observaram o bebê interagindo com essas pessoas? Em quanto deste tempo ocorreram birras? (Funções da pergunta: (a) obtenção de dados sobre o acesso dos pais a outras interações; quanto menor o acesso, maior a chance de a descrição ser imprecisa; (b) pelo questionamento, também colocar a descrição em cheque. ${ }^{3}$ )

- Quando o bebê não faz manha? O que mais ele faz em vez disso? (Funções da pergunta: (a) obtenção de dados sobre contingências de "não manha"; (b) levar os pais a lembrarem-se de tais contingências para, eventualmente, mudarem

2 Note que as descrições verbais aqui estão sendo tratadas como regras no sentido Skinneriano, ou seja, são descrições de contingências (Skinner, 1957/1992). Nesse sentido, essas descrições fornecem estimulação suplementar às contingências e, no exemplo, os pais podem se comportar em relação ao bebê, em parte, sob controle das regras que têm sobre seu comportamento. Para saber mais, recomenda-se a leitura de Meyer (2000).

3 Neste caso, percebemos o quanto a coleta de dados já é, em certa medida, uma intervenção. Isto também significa que devemos ter cautela e planejar o método de coleta, para não levar a intervenções precipitadas. suas regras sobre o bebê e atentarem mais para ele nessas situações.)

- Quando o bebê faz manha, qual é a sua condição em relação aos eventos ambientais não sociais? (Por exemplo, o bebê está mais agasalhado ou menos do que o supostamente necessário em relação à temperatura ambiente? Ou há indícios de privação alimentar, considerando a passagem do tempo entre sua última refeição e o início do choro?)

Veja uma possível descrição de contingências que podemos obter a partir destas perguntas, supondo que as manhas ocorram mais com a mãe do que com o pai e não com a educadora. A título de ilustração, vamos supor também que nossas perguntas nos levaram a informações sobre uma nova resposta do bebê: balbuciar/brincar.

\begin{tabular}{|lll|}
\hline Antecedente & Resposta & Consequência \\
\hline Presença da mãe & $\begin{array}{l}\text { Bebê chorando } \\
\text { ("manha") muitas } \\
\text { vezes } \\
\text { Bebê balbuciando, } \\
\text { brincando }\end{array}$ \\
Presença do pai & $\begin{array}{l}\text { Bebê chorando } \\
\text { ("manha") pouco } \\
\text { Bebê balbuciando, } \\
\text { brincando } \\
\text { Presença da } \\
\text { educadora }\end{array}$ \\
$\begin{array}{l}\text { Bebê chorando } \\
\text { ("manha") rara- } \\
\text { mente } \\
\text { Bebê balbuciando, } \\
\text { brincando }\end{array}$ \\
\hline
\end{tabular}

Agora já temos mais informações do que no início, mas ainda podemos levantar outras bastante importantes, como, por exemplo, horários em que a manha ocorre e outros aspectos que a tornam mais prováveis, como fome, sede, frio, desconforto, barulho, sujeira, sono ou isolamento social. Por que a presença da mãe faria o bebê emitir o choro "do tipo manha" em maior frequência do que a presença do pai e, mais ainda, da educadora? Esta pergunta é muito interessante pois, embora não saibamos as consequências dessas respostas em cada contexto, a variação da frequência nos diz que provavelmente a mãe reforça mais a manha do que o pai - o qual, por sua vez, reforça mais do que a educadora. Mas 
qual seria a consequência reforçadora liberada por cada um? Lembre-se da mesma pergunta feita no exemplo do gato: haveria reforçadores positivos? E negativos?

Quem já atendeu, observou ou cuidou de um bebê terá relativa facilidade em obter dados sobre as consequências por meio de observação. $\mathrm{O}$ bebê suja a fralda, chora, a mãe se aproxima, checa e troca a sua fralda. Mas, neste caso, não estaríamos falando de manha e sim de um início de comunicação (e.g., "Estou sujo, me troque"), dentro de suas capacidades para a idade. Para se caracterizar manha ou birra, tipicamente (a) o reforço social deve estar presente e ser o principal reforço, ainda que não sozinho e/ou (b) o reforço negativo se relaciona à fuga/esquiva de algum tipo de demanda também social.

\section{Observe:}

\begin{tabular}{|c|c|c|}
\hline Antecedente & Resposta & Consequência \\
\hline $\begin{array}{l}\text { Presença da } \\
\text { mãe } \\
\text { Bebê no berço }\end{array}$ & $\begin{array}{l}\text { Bebê chorando } \\
\text { ("manha") muitas } \\
\text { vezes } \\
\text { Bebê balbuciando, } \\
\text { brincando }\end{array}$ & $\begin{array}{l}\text { Mãe pega o bebê } \\
\text { no colo }(\mathrm{Sr}+) \\
\text { ? }\end{array}$ \\
\hline $\begin{array}{l}\text { Presença do pai } \\
\text { Bebê no berço }\end{array}$ & $\begin{array}{l}\text { Bebê chorando } \\
\text { ("manha") pouco } \\
\text { Bebê balbuciando, } \\
\text { brincando }\end{array}$ & $\begin{array}{l}\text { Pai pega o bebê } \\
\text { no colo }(\mathrm{Sr}+) \\
\text { ? }\end{array}$ \\
\hline $\begin{array}{l}\text { Presença da } \\
\text { educadora } \\
\text { Bebê no berço }\end{array}$ & $\begin{array}{l}\text { Bebê chorando } \\
\text { ("manha") rara- } \\
\text { mente } \\
\text { Bebê balbuciando, } \\
\text { brincando }\end{array}$ & $\begin{array}{l}\text { Educadora man- } \\
\text { tém o bebê no } \\
\text { berço (Ext) } \\
?\end{array}$ \\
\hline
\end{tabular}

Temos, agora, uma diferença evidente entre as consequências dadas pelos pais e pela educadora, fortalecendo a hipótese da atenção social, dada de uma determinada forma (i.e., colo), como uma variável importante na manutenção da manha do bebê. O bebê, eventualmente, pode fazer manha para a educadora (reforçamento levando a uma generalização de estímulos), mas logo aprende que, com esta pessoa, manha não leva a colo (extinção levando a uma discriminação de estímulos). Mas por que o bebê faria mais manha com a mãe do que com o pai? Esta seria a próxima pergunta essencial.

Podem existir outras inúmeras variáveis na raiz desta explicação. Uma delas inclui a magnitude do reforço, a partir da topografia do "pegar no colo". Em outras palavras, a mãe pega no colo, aperta, faz carinho, canta, conversa e embala o bebê. Enquanto isso, o pai pega no colo e somente espera, conversando pouco. Outra variável pode ser o tempo de contato do bebê com a mãe em relação ao pai. Mas, para fins didáticos, enfatizaremos a diferença entre o reforço dado para a manha e para outras respostas (no caso, balbuciar e brincar). Novamente, via observação, devemos ir atrás não apenas das contingências relacionadas ao problema, mas das contingências de comportamentos alternativos:

\begin{tabular}{|c|c|c|}
\hline Antecedente & Resposta & Consequência \\
\hline $\begin{array}{l}\text { Presença da } \\
\text { mãe } \\
\text { Bebê no berço }\end{array}$ & $\begin{array}{l}\text { 1.Bebê chorando } \\
\text { ("manha") muitas } \\
\text { vezes } \\
\text { 2.Bebê balbuciando, } \\
\text { brincando }\end{array}$ & $\begin{array}{l}\text { 1.Mãe pega no } \\
\text { colo, aperta, faz } \\
\text { carinho, can- } \\
\text { ta, conversa e } \\
\text { embala o bebê } \\
\text { (Sr+) } \\
\text { 2.Mãe vai fazer } \\
\text { suas coisas (Ext) }\end{array}$ \\
\hline $\begin{array}{l}\text { Presença do } \\
\text { pai } \\
\text { Bebê no berço }\end{array}$ & $\begin{array}{l}\text { 1.Bebê chorando } \\
\text { ("manha") pouco } \\
2 . \text { Bebê balbuciando, } \\
\text { brincando }\end{array}$ & $\begin{array}{l}\text { 1.Pai pega no } \\
\text { colo e conversa } \\
\text { pouco com o } \\
\text { bebê }(\mathrm{Sr}+\text { ) } \\
\text { 2.Pai conversa } \\
\text { com bebê }(\mathrm{Sr}+\text { ) }\end{array}$ \\
\hline $\begin{array}{l}\text { Presença da } \\
\text { educadora } \\
\text { Bebê no berço }\end{array}$ & $\begin{array}{l}\text { 1.Bebê chorando } \\
\text { ("manha") raramente } \\
2 . \text { Bebê balbuciando, } \\
\text { brincando }\end{array}$ & $\begin{array}{l}\text { 1.Educadora } \\
\text { mantém o bebê } \\
\text { no berço (Ext) } \\
2 . \text { Educadora } \\
\text { conversa com } \\
\text { bebê }(\mathrm{Sr}+)\end{array}$ \\
\hline
\end{tabular}

Agora temos as informações completas e podemos descrever a tríplice contingência. Como você descreveria o quadro anterior? Faça sua tentativa, escrevendo em um papel e depois leia atentamente uma forma de descrevê-lo, de maneira completa e operacionalizada: 
Quando o bebê está no berço e a mãe está por perto, ele chora frequentemente e a mãe o pega no colo enquanto aperta, faz carinho, canta, conversa e o embala, o que provavelmente reforça positivamente a resposta de chorar, caracterizada como manha por sua topografia e por ter como principal consequência a atenção social. Nas mesmas condições, quando o bebê balbucia ou brinca no berço, a mãe continua fazendo suas atividades, não havendo consequência social para estas respostas, o que caracterizaria extinção. Como resultado, o bebê faz muita manha, especialmente com a mãe.

Quando o bebê está no berço e o pai está por perto, ele também chora e o pai também o pega no colo enquanto conversa somente um pouco (reforçamento positivo), mas o pai dá atenção social a outras respostas, como quando conversa com o bebê balbuciando ou brincando no berço (reforçamento positivo). Como resultado, o bebê faz alguma manha, mas em menor frequência/intensidade (comparado à situação com a mãe), uma vez que outras respostas também produzem o mesmo reforço.

Por fim, quando o bebê está com a educadora, ela o mantém no berço quando ele faz manha, caracterizando uma relação de extinção e, ainda, conversa e interage com ele quando balbucia ou brinca no berço, caracterizando uma relação de reforçamento positivo. Como resultado, o bebê raramente faz manha com a educadora.

Quanto mais operacionalizada a descrição, mais as informações são compreendidas, o que se torna pré-requisito para o planejamento da intervenção, conforme veremos mais adiante. Algumas dessas informações poderiam ser ainda mais precisas, como, por exemplo, o significado de "muita manha" (e.g., a cada meia hora, em média). Quanto tempo caracteriza um episódio de manha? Tem a ver com a intensidade do choro (estridente, contínuo, sem lágrimas, etc.)? Por ora, é importante destacar que a descrição inclui: (a) os três termos da contingência, ainda que alguns elementos possam ser descritos como hipóteses ainda não testadas; (b) a relação entre os termos; (c) a função das consequências identificadas e (d) informações adicionais como, no caso, as contingências associadas ao comportamento alternativo.

As manhas e as birras do bebê dificilmente trariam problemas para ele, do modo como foram des- critas neste quadro. Então, por que deveriam ser alvo de intervenção do terapeuta? $\mathrm{Na}$ análise do comportamento, não consideramos as respostas dos clientes como "adequadas" ou "inadequadas"; elas simplesmente existem e podem ser explicadas por contingências passadas (que as instalaram) e atuais (que as mantêm). Contudo, algumas consequências das respostas podem incluir punição para si ou para o outro, a curto, médio ou longo prazo. Por esse motivo, uma resposta ou, usualmente, uma ou mais classes de respostas tornam-se alvo de intervenção do analista. A identificação das contingências controladoras de uma resposta serve, em última análise, para melhor controlá-las, ou seja, para manipular variáveis de modo a aumentar a probabilidade de reforço positivo e a reduzir a probabilidade de punição (ambos imediatos ou atrasados). Skinner (1953/1970) é categórico ao afirmar que o controle existe, quer gostemos quer não gostemos. O objetivo da ciência do comportamento é trazer este controle para nós mesmos, da maneira menos coercitiva possível, em vez de deixá-lo ao acaso ou nas mãos de tiranos.

Posto isso, agora avançaremos mais um passo na análise, supondo que o padrão de manha do bebê foi cada vez mais modelado pelos pais ou por outros cuidadores, até que se tornou uma "criança birrenta", o que nos leva ao terceiro exemplo apresentado no início do texto: "Um menino birrento de sete anos, com autoestima baixa". A autoestima baixa é um termo genérico muito utilizado em nossa cultura, podendo se referir a tantos comportamentos quanto se possa imaginar, uma vez que não descreve nenhuma resposta aberta e nenhum sentimento específico (no máximo, sabemos que deve se referir a algum tipo de sensação ruim). Quando o repertório dos analistas começa a ser modelado em cursos de formação, contudo, não raro a "autoestima baixa" surge como descrição de algum termo da contingência, seja antecedente, resposta ou consequência. Dessa forma, que perguntas seriam necessárias no campo das respostas? O que você espera obter? Sem lançar mão de nenhuma hipótese incipiente, a pri-

4 Embora manha e birra sejam semelhantes, coloquialmente parece mais provável que bebês sejam descritos como "manhosos" e crianças como "birrentas". O texto faz tal diferenciação, passando a partir desse ponto a utilizar o termo birra para analisar a criança. 
meira missão do analista neste caso deveria ser a obtenção de dados objetivos sobre respostas abertas (ações observáveis) e encobertas (sentimentos e pensamentos) do menino. Algumas perguntas que poderiam ser formuladas aos cuidadores incluem:

- Como é essa autoestima baixa? Fale-me mais sobre essa autoestima baixa.

- Como ele se sente e o que ele pensa? Ele chega a relatar isso (e para quem)? Ou é você que percebe, mas ele não fala?

- Como ele fica quando está com autoestima baixa? O que ele fica fazendo?

- Quanto tempo dura esse período em que você o percebe com autoestima baixa?

Há momentos em que ele parece melhor ou, ao menos, não tão pior? Como ele fica nesses momentos?

Observe que, acima de tudo, nenhuma das perguntas contém em si algum tipo de resposta. São as chamadas perguntas abertas, que induzem o interlocutor a discorrer amplamente e sem direcionamento sobre determinado tema (cf. Hill, 1999). A diferença entre perguntar "Como ele se sente?" e "Ele fica triste?" é que a pergunta aberta, como antecedente da resposta, trará menor risco de alterar a sua probabilidade numa dada direção. A pergunta "Ele fica triste?" pode levar o interlocutor a não considerar outras propriedades para relatar (ficando sob controle somente do triste), ou mesmo a responder aquilo que seria mais correto, presumindo a opinião de quem fez a pergunta. Com estas perguntas, vamos agora supor um grupo de informações alocadas no quadro a seguir:

\begin{tabular}{lll}
\hline Antecedentes & Respostas & Consequências \\
\hline$?$ & Abertas: Fica & $?$ \\
& quieto, tranca-se \\
& no quarto, come \\
& demasiadamente, \\
& provoca a irmã, cho- \\
& ra e reclama sobre \\
& o quanto é infeliz \\
& Encobertas: Pensa \\
& que é infeliz e que \\
& ninguém gosta dele; \\
& sente raiva, tristeza \\
& e irritação \\
\hline
\end{tabular}

As respostas do menino, agora aos sete anos, possuem maior complexidade em relação ao chorar na época em que era bebê. Dadas as respostas, agora mais descritivas, como você faria para investigar os antecedentes contextuais das mesmas? Pelo conteúdo das respostas, podemos inferir que há - no mínimo - algum tipo de aversividade nesta contingência (o que seria uma hipótese forte). Algumas situações aversivas relativamente comuns poderiam ser: (a) frustrações de modo geral, como receber o doce menor na sobremesa, dificuldades na tarefa de casa ou não ser escolhido para o time de futebol na aula de Educação Física; (b) demandas de modo geral, como ser solicitado a retirar os pratos da mesa após o almoço, a guardar os brinquedos ou a ler sua tarefa em voz alta para a classe e (c) demandas por relações socialmente habilidosas, desde interações amistosas a provocações que requereriam desenvoltura, colocação de limites ou tolerância a chacotas. Podemos imaginar também uma generalização destas respostas (aliada à falta de repertório, de reforço ou de oportunidade para respostas alternativas), levando a criança a emiti-las não apenas em situações aversivas, mas também nas neutras ou amistosas, produzindo reforçamento positivo, mas também punição ou extinção de maneira intermitente, conforme será demonstrado no próximo quadro de tríplice contingência. Assim, a simples presença do outro pode ser um antecedente para respostas de aproximação agressivas, que incitam uma discussão (e.g., provocar a irmã). Além disso, como ilustrado no exemplo do bebê, para se caracterizar uma resposta da classe da birra, é necessária a existência de consequências sociais mantenedoras (reforço social e/ou esquiva de demanda). Mas nem todas as respostas listadas no quadro anterior precisam se encaixar na classe de birra. Talvez estejamos tratando de uma classe maior ou de algumas classes diferentes, conforme o quadro se agrava. A partir do exposto, como você preencheria a célula dos antecedentes? 


\section{Observe:}

\begin{tabular}{|c|c|c|}
\hline Antecedentes & Respostas & Consequências \\
\hline $\begin{array}{l}\text { Receber o doce menor na } \\
\text { sobremesa }\end{array}$ & $\begin{array}{l}\text { Reclamar, choramingar } \\
\text { Pensar que ninguém gosta dele }\end{array}$ & Pais dão bronca (Sr+/Sr-) \\
\hline Tarefa de casa difícil & Quebrar o lápis, gritar, choramingar & $\begin{array}{l}\text { Mãe auxilia ou faz a tarefa por ele } \\
\left(\mathrm{Sr}_{+}+\mathrm{S}_{\mathrm{r}-}\right)\end{array}$ \\
\hline $\begin{array}{l}\text { É preterido na escolha dos } \\
\text { membros do time de futebol na } \\
\text { aula de Educação Física }\end{array}$ & $\begin{array}{l}\text { Reclamar, choramingar, empurrar colega, isolar-se } \\
\text { Sentir-se envergonhado }\end{array}$ & $\begin{array}{l}\text { Colegas riem dele e colocam apelidos } \\
\text { pejorativos }\left(\mathrm{Sr}_{-}\right) \text {, professor o retira do } \\
\text { time }\left(\mathrm{S}_{\mathrm{r}+}\right)\end{array}$ \\
\hline Frustrações & Classe de birra & $\begin{array}{l}\text { Atenção social }(\mathrm{Sr}+) \\
\text { Elimina ou adia evento frustrador (Sr-) } \\
\left.\text { Punição (Sr-, } \mathrm{Sr}_{+}+\right)\end{array}$ \\
\hline $\begin{array}{l}\text { Mãe solicita que retire os pra- } \\
\text { tos da mesa }\end{array}$ & $\begin{array}{l}\text { Reclamar, choramingar, emburrar e se recusar a } \\
\text { fazer }\end{array}$ & $\begin{array}{l}\text { Mãe dá sermão ( } \mathrm{Sr}+/ \mathrm{Sr}-) \text { e/ou retira } \\
\text { os pratos por ele (S+-) }\end{array}$ \\
\hline $\begin{array}{l}\text { Pai manda guardar os brinque- } \\
\text { dos }\end{array}$ & Reclamar e falar que só vai guardar mais tarde & $\begin{array}{l}\text { Pai dá sermão }(\mathrm{Sr}+/ \mathrm{Sr}-) \text { e/ou deixa de } \\
\left.\text { insistir ( } \mathrm{S}_{-}-\right) \text {e empregada guarda os } \\
\left.\text { brinquedos ( } \mathrm{Sr}_{-}\right)\end{array}$ \\
\hline $\begin{array}{l}\text { Professora o escolhe para ler a } \\
\text { lição em voz alta na frente dos } \\
\text { colegas }\end{array}$ & $\begin{array}{l}\text { Choramingar, emudecer } \\
\text { Encher os olhos de lágrimas }\end{array}$ & $\begin{array}{l}\text { Professora mantém o pedido (Ext), o } \\
\text { ridiculariza para a sala (Sr-), dá "ponto } \\
\text { negativo" (Sr-) e/ou o libera da tarefa } \\
(\mathrm{S} r)\end{array}$ \\
\hline Demandas gerais & Classe de birra e/ou oposição & $\begin{array}{l}\text { Elimina ou adia a demanda (Sr-); } \\
\text { Atenção social (Sr+); } \\
\text { Punição (Sr-) e extinção (Ext) }\end{array}$ \\
\hline $\begin{array}{l}\text { Colega o chama para jogar um } \\
\text { jogo no recreio }\end{array}$ & $\begin{array}{l}\text { Aceita, mas impõe condições desiguais que o } \\
\text { favorecem }\end{array}$ & $\begin{array}{l}\text { Colega o chama de chato (Sr-), briga } \\
\text { (Sr-) e/ou o expulsa do jogo (Sr-) }\end{array}$ \\
\hline Irmã usando o computador & Aproxima-se e fala que é a sua vez de usar & $\begin{array}{l}\text { Irmã diz que não vai liberar o compu- } \\
\text { tador (Ext) }\end{array}$ \\
\hline $\begin{array}{l}\text { Irmã diz que não vai liberar o } \\
\text { computador }\end{array}$ & $\begin{array}{l}\text { Empurra a irmã e procura a mãe choramingando e } \\
\text { acusando a irmã } \\
\text { Pensa que é sempre injustiçado }\end{array}$ & $\begin{array}{l}\text { Irmã chora }\left(\mathrm{Sr}_{+}+\right) \text {e libera computador } \\
(\mathrm{Sr}+) \text {, mãe dá bronca nele }(\mathrm{Sr}+/ \mathrm{Sr}-) \\
\text { ele ganha o computador }\left(\mathrm{Sr}_{+}\right) \text {ou fica } \\
\text { de castigo }\left(\mathrm{S}_{+}+\right)\end{array}$ \\
\hline $\begin{array}{l}\text { Demandas por respostas } \\
\text { socialmente habilidosas }\end{array}$ & Classe de birra, oposição e/ou agressão & $\begin{array}{l}\text { Atenção social }(\mathrm{Sr}+) \text { / ganhos especí- } \\
\text { ficos }\left(\mathrm{Sr}_{+}\right) \\
\text {Punição mais severa (Sr-/Sr+) }\end{array}$ \\
\hline
\end{tabular}


O quadro acima traz duas novidades, em termos de forma de organização e representação das informações. A primeira delas é a especificação de exemplos de contingências, culminando nas classes gerais correspondentes (células em cinza). A segunda delas, no último exemplo (i.e., interação com irmã para usar o computador), é um modo de mostrar cadeias maiores de resposta, quando uma consequência para determinada resposta torna-se antecedente para a próxima.

Em termos de complexificação da contingência, traz também duas condições importantes. A primeira delas é que uma dada resposta pode produzir várias consequências, simultaneamente ou de forma alternada (especificadas pela expressão $e / o u$ ). Outra é que uma única consequência pode ter mais de uma função (especificada nas sinalizações $S r+/ S r-$-, $S r-/ S r+$ ou qualquer outra combinação possível). Isso significa que tais estímulos têm múltiplas propriedades, podendo haver funções diferentes para cada uma delas. A consequência "Pais dão bronca", por exemplo, pode ter não apenas propriedades aversivas - o conteúdo da ação dos pais, caracterizado como bronca -, mas também propriedades reforçadoras - a atenção despendida pelos pais à criança enquanto dão a bronca -, assinaladas, respectivamente, como $\mathrm{Sr}$ - e $\mathrm{Sr}+$. Deste modo, compreendemos mais facilmente como certas consequências aparentemente "ruins" podem manter o responder, ou seja, reforçá-lo.

Com relação à compreensão do caso, é necessário fazer algumas considerações, a partir de uma pergunta muito importante, a que você pode tentar responder: Como você compararia as contingências descritas quando o indivíduo era um bebê e agora, aos sete anos? Para responder a esta pergunta, você pode iniciar simplesmente listando (descrevendo) as diferenças observadas e, em seguida, procurar as explicações funcionais para elas. Algumas diferenças poderiam ser listadas da seguinte maneira:

- Quando bebê, as possibilidades de interação são menores (mãe, pai e educadora) do que aos sete anos (mãe, pai, professores e colegas), bem como a diversidade de ambientes aos quais pode ter acesso o bebê (grande parte do tempo no berço ou no colo) e a criança (todos os espaços da casa, sala de aula, quadra, etc.).

- Quando bebê, as possibilidades de respostas são mais restritas (chorar, balbuciar, brincar) e as da criança são mais variadas e complexas (conversar, fazer lição, usar computador, jogar, praticar esportes, etc.).

- Ainda nesse sentido, os comportamentos-alvo do indivíduo também se complexificam: inicialmente, pertenciam à classe de "fazer manha" e incluíam basicamente o chorar; aos sete anos, são tão variados (choramingar, gritar, reclamar, quebrar coisas, empurrar, negar-se, discutir, acusar, pedir, impor) que podem pertencer não apenas à manha ou birra, mas à oposição e à agressão.

- Conforme já exposto, as consequências dadas às respostas do bebê são mais simples (pegar no colo) do que para as da criança (ser ajudado, ser liberado da tarefa, zombarem dele, receber castigo, sermão ou bronca, ganhar ponto negativo, etc.).

Assim, em linhas gerais, podemos dizer que a vida da criança ficou mais complexa, o que tem uma correlação positiva com o aumento de suas possibilidades de responder, de agir no mundo. Contudo, se os padrões de interação continuaram os mesmos de quando era um bebê, é provável que passe a ter mais problemas, sobretudo porque muitas pessoas (e até mesmo os pais) não mais reforçam como outrora aquelas respostas que inicialmente eram reforçadas, ou alternam reforço com punição/extinção. A avaliação considera, pois, que as contingências responsáveis pela instalação de um comportamento nem sempre são as mesmas responsáveis por sua manutenção no presente. Ainda em termos da avaliação funcional de tais mudanças, diz-se que houve principalmente um processo de generalização: aquela classe de respostas, antes emitida somente diante dos pais e raramente da educadora, agora é emitida em outros contextos e diante das mais diversas pessoas - em parte porque a criança não aprendeu respostas alternativas e este era seu principal repertório de interação. Outro ponto da análise é que, como nem todas as pessoas com quem o menino se relaciona reforçam o padrão de birra/oposição/agressão, há alguns termos da contingência em que a consequência principal é a punição ou, no mínimo, a extinção. Demonstrase, assim, que aquela classe de comportamentos já detectada quando ele era bebê seria (e ainda é), sim, 
alvo de intervenção por produzir sofrimento a longo prazo.

A partir desta análise, o que você acha que pode acontecer com o padrão comportamental do menino daqui para frente? Uma boa maneira de se levantar alternativas para a resposta é analisar suas interações atuais a partir das próprias definições de reforçamento, punição e extinção, as três consequências de suas respostas. O que o reforço desse padrão poderá produzir? A resposta reforçada se mantém, ou seja, o menino continua emitindo respostas de birra, oposição e agressão nos mais diversos contextos em que há algum tipo de reforço. O que a extinção desse padrão poderá produzir? Neste caso, mais complicado, devemos lembrar que as consequências de uma relação de extinção são inicialmente o aumento da frequência e da diversidade da topografia da resposta, ocorrendo decréscimo apenas se a extinção mantiver-se em todo o processo. Caso contrário, o menino fará mais birras, tornar-se-á mais agressivo e em algum momento será reforçado novamente, piorando o quadro. Dizemos que, nessas situações, o ambiente acaba modelando a piora da criança, o que provavelmente já teria acontecido antes, explicando a evolução de sua piora até o momento em que ele se encontra. O que a punição para esse padrão poderá produzir? Um dos efeitos seria a supressão temporária da resposta (Catania, 1999), mas também vários efeitos colaterais, como contracontrole, reações emocionais, fuga/esquiva do agente punidor e desamparo (Sidman, 2001). O maior problema dos três tipos de consequências pode ser, na verdade, a falta de alternativas, quando a criança não tem oportunidade, nem repertório, nem reforço suficiente para a emissão de respostas de outras classes mais apropriadas. Ao final desta avaliação, como você descreveria esse quadro de tríplice contingências? Observe, agora, uma versão simplificada desta descrição:

Diante de antecedentes de frustração (como uma tarefa de casa difícil ou ser preterido na escolha dos membros do time de futebol na aula de Educação Física), a criança emite respostas da classe de birra (e.g,, choramingar e isolar-se) e obtém diversos tipos de consequências, algumas reforçadoras (mãe faz a tarefa por ele $[\mathrm{Sr}+/ \mathrm{Sr}-])$ e outras punitivas (colegas riem dele [Sr]). Usualmente, a maior proporção de punição parece ser no contexto escolar, como tam- bém se pode perceber no caso de situações de demanda, como em: pai manda guardar os brinquedos e professora o escolhe para ler a lição em voz alta na frente dos colegas. No primeiro caso, o menino sente muita vergonha e suas tentativas de se esquivar da demanda (reclamar, choramingar, emudecer) produzem diferentes consequências, como a efetiva esquiva (pai deixa de insistir e empregada guarda os brinquedos [Sr-]) e a atenção social ( $\mathrm{Sr}+$ ) com componentes aversivos (Sr-) quando o pai "dá sermão". No segundo exemplo, em contexto escolar, há alguma esquiva da tarefa de leitura ( $\mathrm{Sr}=$ ), mas, muitas vezes, a professora mantém o pedido (Ext) ou aplica punições, ao ridicularizar a criança diante da sala (Sr-) ou dar ponto negativo (Sr). Por fim, situações de demanda por respostas socialmente habilidosas também parecem ocasionar respostas semelhantes, como um convite de colega para jogar no recreio e a necessidade de negociar o uso do computador com a irmã. No primeiro caso, a criança, sem repertório alternativo bem desenvolvido, pode impor ao colega condições desiguais que o favorecem no jogo, produzindo punições (colega o chama de chato [Sr-], briga [Sr-] e/ou o expulsa do jogo [ $\mathrm{Sr}+]$ ). No exemplo de interação com a irmã, é provável que ocorra uma cadeia de respostas em que, diante da recusa da irmã às suas primeiras tentativas de obter o computador, ele pensa que ninguém gosta dele, enquanto parte para respostas de topografia mais agressiva (empurrá-la) ou de "birra" (choramingar para a mãe, acusando a irmã), produzindo diferentes tipos de consequências, algumas reforçadoras (irmã chora e libera o computador), outras mistas (mãe dá bronca $[\mathrm{Sr}+/ \mathrm{Sr}-]$ ) e outras com intermitência entre reforço (obter o computador $[\mathrm{Sr}+]$ ) e punição (ficar de castigo [ $\mathrm{S} r+]$ ). Em suma, embora produzindo várias punições, o padrão do responder se mantém por também produzir reforçamento e, como hipótese, pode-se inferir que se fortaleça devido ao esquema intermitente desses reforços.

Neste ponto, podemos afirmar que a nossa avaliação do caso está bastante completa, podendo, é claro, ser ainda mais aprimorada conforme se obtenham mais dados que confirmem, refutem ou detalhem as hipóteses funcionais já estabelecidas. Agora, passaremos a um breve exercício de previsão de intervenções, supondo que a criança em questão tenha sido encaminhada à terapia 
analítico-comportamental. Este exercício não será apresentado em função de especificidades da intervenção com crianças, mas sim dos diversos procedimentos e técnicas disponíveis e passíveis de uso pelo analista para diferentes casos, independentemente da faixa etária.

\section{Planejamento da Intervenção}

Antes de iniciarmos nossa previsão de intervenção sobre os comportamentos do menino, devemos compilar quais intervenções podem ser utilizadas em geral e qual o foco de cada uma delas. Podemos classificar os procedimentos possíveis de acordo com seu foco sobre a modificação do antecedente ou da consequência da resposta ${ }^{5}$. Neste artigo, serão enfocadas as intervenções sobre as consequências da resposta, esclarecendo, contudo, de que maneira elas também levam a uma modificação de sua relação com o antecedente.

Quais procedimentos sobre as consequências você conhece? Neste artigo, serão abordados os procedimentos de reforçamento diferencial (e seus subtipos) e modelagem, discutindo-se suas variações em termos de reforçamento natural e arbitrário (Ferster, 1967). Outras intervenções, com foco em extinção e punição, não pertencem à nossa análise neste momento, por um motivo especial: por definição, elas não ensinam diretamente a emissão de novos comportamentos.

O reforçamento diferencial $\left(\mathrm{DR}^{6}\right)$ consiste na apresentação de consequências reforçadoras, a depender de qual resposta é emitida pelo cliente (Vollmer \& Iwata, 1992). Tradicionalmente, diz-se que o DR seria composto do reforçamento das respostas que se pretende aumentar de frequência, combinado ao não reforçamento (extinção) das respostas que se pretende diminuir. Na prática clínica, contudo, o DR não ocorre de modo tão dicotômico pois, em uma interação social natural, é difícil não haver nenhum tipo de reforço para uma resposta.

5 Para informações detalhadas sobre esta classificação e sobre cada uma das principais técnicas sobre antecedentes e consequências, recomendo a leitura de Del Prette e Almeida (2011).

6 Do inglês, differencial reinforcement. Utiliza-se a sigla referente à terminologia em inglês, uma vez que a comunidade brasileira de analistas do comportamento usualmente mantém as siglas originais para os diferentes reforços diferenciais, como DRA, DRO e DRI, citados mais adiante.
A mera presença do interlocutor pode ser, em alguma medida, reforçadora. Dito de outro modo, não há como o clínico não reforçar, em absoluto, uma dada resposta. Assim, é preferível falar em termos de diferentes magnitudes de reforço: um reforço em maior magnitude para algumas respostas e em menor para outras (Catania, 1999). A escolha de quais são as outras respostas (que recebem reforço em menor magnitude) leva a alguns subtipos de DR, cujos mais conhecidos e úteis ao clínico são (Catania, 1999):

1. Reforçamento diferencial de outras respostas ou DRO (Differencial reinforcement of others): reforçam-se todas as outras respostas do indivíduo e as respostas-queixa7 recebem o menor reforçamento possível.

2. Reforçamento diferencial de respostas alternativas ou DRA (Differencial reinforcement of alternatives): reforçam-se somente as respostas alternativas (com igual função, a despeito da topografia) e as respostas-queixa recebem o menor reforçamento possível.

3. Reforçamento diferencial de respostas incompatíveis ou DRI (Differencial reinforcement of incompatibles): reforçam-se respostas fisicamente incompatíveis de serem emitidas simultaneamente às respostas-queixa - as quais, por sua vez, recebem o menor reforçamento possível.

Del Prette e Almeida (2011) citam o exemplo da intervenção sobre tricotilomania (i.e., compulsão por arrancar cabelos) na distinção entre DRO, DRA e DRI. O DRO seria o reforçamento de todas as outras respostas, exceto a de arrancar cabelos. O DRA seria o reforçamento de respostas que produzam função igual à de arrancar cabelos, o que requer uma análise de contingências cuidadosa. Supondo que a função seja de autoestimulação tátil, por exemplo, uma resposta como a de apertar uma bolinha macia poderia ter a mesma função. O DRI seria o reforçamento de respostas fisicamente incompatíveis às de arrancar os cabelos, ou seja, qualquer coisa que ocupe ambas as mãos do indivíduo.

Já a respeito da modelagem, pode-se dizer que ela envolve um reforçamento diferencial de respos-

7 Respostas-queixa são aquelas que o indivíduo emite e que deve ter sua frequência diminuída, passando a ser este um dos objetivos da terapia, a partir de uma análise de contingências. 
tas. No entanto, esse procedimento é realizado ao longo de um continuum a partir das respostas que o indivíduo já emite, gradualmente se aproximando da resposta final. Leia atentamente a definição de Catania (1999):

Modificação gradual [ênfase adicionada] de alguma propriedade do responder (frequentemente, mas não necessariamente, a topografia) pelo reforço diferencial [ênfase adicionada] de aproximações sucessivas a uma classe operante alvo. A modelagem é empregada para produzir respostas que, devido a um nível operante baixo e/ou devido à complexidade, não seriam emitidas ou seriam emitidas somente depois de um tempo considerável. A variabilidade [ênfase adicionada] do responder que segue o reforço geralmente provê as oportunidades para o reforço de outras respostas que se aproximem mais de perto do critério [ênfase adicionada] que define a classe operante alvo. A modelagem é uma variedade de seleção operante. (p. 411)

A modelagem é, certamente, o principal procedimento do terapeuta analíticocomportamental para manipular as consequências do responder. Seja por meio de DRO, DRA, DRI ou qualquer outro tipo ou combinação, modelar respostas requer habilidades refinadas de observação, análise, timing para intervir no momento exato, sutileza para fazê-lo do modo mais natural possível, atenção para os efeitos desta intervenção e ajustes e reajustes constantes para efetuar a progressão de suas etapas. A possibilidade de as respostas serem modeladas pode ser um trunfo ou um perigo, a depender de como isso é realizado, com qual finalidade e com que nível de consciência daquele que manipula as contingências. Relatos verbais, por exemplo, podem ser modelados dando a falsa impressão ao clínico de que seu cliente melhorou quando, na verdade, somente parou de se queixar em sessão e passou a contar mais frequentemente aquilo que o terapeuta queria ouvir (e reforçava). Habilidades interpessoais podem ser modeladas na própria interação terapêutica, produzindo modos de se relacionar jamais experimentados anteriormente pelo cliente. Quanto maior a consciência do terapeuta sobre este processo, mais poderá aproveitar as oportunidades do período da sessão para produzir mudanças graduais, mas significativas.

Antes de aplicarmos estas considerações ao caso do "menino com autoestima baixa", um último ponto merece ser destacado: o significado de reforçamento natural e arbitrário. De modo geral (embora haja exceções, como na economia de fichas, conforme Ayllon \& Azrin, 1968), é desejável que o reforço liberado pelo terapeuta se aproxime mais do natural e menos do arbitrário. $\mathrm{O}$ reforço natural, em contingências sociais, é aquele que mais se assemelha ao modo como a sociedade (e, especificamente, o subgrupo em que o cliente se insere) naturalmente reforçaria determinadas respostas. Falar sobre um assunto com clareza, por exemplo, costuma fazer com que o interlocutor se mantenha atento e interessado (reforço natural), e não elogios sobre esta fala (reforço artificial ou arbitrário). Analogamente, ser gentil aumenta a probabilidade de agradecimentos ou gentileza recíproca; defender seus direitos de modo assertivo reduz a probabilidade de que abusem de sua boa vontade (ou inassertividade) e também reduz a probabilidade de brigas mais graves, caso a defesa fosse agressiva.

O terapeuta analítico-comportamental em início de formação, muitas vezes, sucumbe à tentação de utilizar elogios ou exclamações artificialmente entusiasmadas, como meio de (supostamente) reforçar as respostas de seus clientes e, às vezes, realmente acredita ser este o modo de intervenção na abordagem. A importância do reforço natural (ver Horcones, 1992; Santos \& de Rose, 1999), contudo, vem da própria análise de contingências: quanto mais naturais as reações do terapeuta, maior a probabilidade de generalização do novo repertório do cliente para o ambiente de seu dia a dia. De todo modo, há um tipo especial de consequência que terapeutas analíticocomportamentais provêm aos seus clientes: a interpretação de seus comportamentos. Em certo sentido, a interpretação pode ser considerada menos natural, por ter menos semelhança com as interações fora do setting terapêutico. Terapeutas interpretam (ou levam o cliente a interpretar) comportamentos emitidos em sessão, ou o relato de sua ocorrência fora desta, como modo de aumentar o controle verbal do cliente sobre os mesmos, conforme descrito por Skinner (1957/1992). Descrições verbais de contingências são o que 
denominamos de autoconhecimento e, em última instância, auxiliam no autocontrole e na autonomia do cliente para controlar as variáveis de suas próprias ações. Tais descrições podem participar das contingências futuras como suplementações verbais (Meyer, 2000; Skinner, 1957/1992), no campo do antecedente. Por ora, é importante lembrar somente que descrever, parafrasear, interpretar ou levar o cliente a interpretar é uma consequência para as respostas do cliente típica do contexto terapêutico; portanto, pouco semelhante a seu ambiente do dia a dia. Contudo, é uma intervenção valiosa e mais útil que o uso de elogios. Consequências naturais (ou intrínsecas) da interação e uso de descrição e interpretação das contingências são dois modos de intervir característicos da psicoterapia analítica funcional (funcional analytic psychotherapy [FAP]), proposta de Kohlenberg e Tsai (2001), que enfatiza a relação terapêutica como o principal instrumento de mudança. A proposta da FAP salienta também o papel do feedback genuíno e profundo do terapeuta a respeito de como se sente durante a interação com seu cliente, contingente aos seus avanços em termos de comportamentos que denotam aproximação e intimidade na relação (Tsai, Kohlenberg, Kanter, Kohlenberg, Follette \& Callaghan, 2009).

A partir desta breve análise da modelagem e do reforçamento diferencial, passamos agora à previsão de algumas possíveis intervenções sobre as consequências do responder no atendimento do menino anteriormente analisado. Como você planejaria tais intervenções? Uma vez que temos uma análise de contingências bem detalhada, esta etapa se torna um pouco mais fácil. Para planejar as intervenções, primeiramente esquematizaremos quais comportamentos necessitam ter sua frequência reduzida (comportamentos-queixa) e quais precisam ser fortalecidos (comportamentos de melhora).
Observe:

\begin{tabular}{lll}
\hline & $\begin{array}{l}\text { Comportamentos- } \\
\text { queixa }\end{array}$ & $\begin{array}{l}\text { Comportamentos } \\
\text { de melhora }\end{array}$ \\
\hline $\begin{array}{l}\text { Classes } \\
\text { de ordem } \\
\text { inferior }\end{array}$ & $\begin{array}{l}\text { Classes de birra, } \\
\text { oposição e agressão: } \\
\text { choramingar, reclamar, } \\
\text { procrastinar, gritar, que- } \\
\text { brar coisas, recusar-se, } \\
\text { impor e empurrar }\end{array}$ \\
& $?$ \\
$\begin{array}{l}\text { Classes } \\
\text { de ordem } \\
\text { superior }\end{array}$ & $\begin{array}{l}\text { Classes de ordem } \\
\text { superior: forte controle } \\
\text { das consequências } \\
\text { imediatas, atribuição ao } \\
\text { outro como responsá- } \\
\text { vel por solucionar seus } \\
\text { problemas }\end{array}$ \\
& \\
\hline
\end{tabular}

O quadro lista os comportamentos-queixa já identificados anteriormente, mas traz uma novidade importante para o processo de modelagem: a identificação de classes de ordem superior. A classe de ordem superior é definida por Catania (1999) como

a classe operante que inclui, dentro dela, outras classes que podem, por sua vez, funcionar como operantes, por exemplo, quando a imitação generalizada inclui todas as imitações componentes que poderiam ser separadamente reforçadas. As classes de ordem superior podem ser uma fonte de comportamentos novos (como na imitação de um comportamento que o imitador nunca viu antes). As contingências operam diferentemente para a classe de ordem superior e para as classes que a compõem. Por exemplo, se todas as instâncias de Imitação são reforçadas, exceto as de uma classe componente ... aquela classe pode mudar com a classe de ordem superior, e não com as contingências planejadas para ela ... O controle pelas contingências programadas para a classe de ordem superior define a pertinência à classe; as classes componentes são consideradas, às vezes, como insensíveis às contingências de ordem inferior programadas para elas. Uma classe de ordem superior pode ser chamada de uma classe generalizada, no sentido de que as contingências programadas 
para alguns de seus componentes se generalizam para todos os outros. Emparelhamento com o modelo generalizado e o comportamento verbalmente controlado são exemplos de classes de ordem superior. (p. 389)

Todas as subclasses birra, oposição e agressão guardam propriedades comuns às classes de ordem superior, descritas em termos de "forte controle das consequências imediatas" e "atribuição ao outro como responsável por solucionar seus problemas". Seguindo-se o exposto por Catania (1999), as respostas dessas classes inferiores podem se manter devido ao controle das classes superiores. Assim, sem uma mudança das classes superiores, torna-se mais difícil que as birras, a oposição e a agressão cessem. É necessário planejar não apenas quais seriam especificamente os repertórios mais efetivos para as situações em que a criança vive, mas também quais seriam as classes de ordem superior alternativas. Como você preencheria os campos sobre comportamentos de melhora?

\begin{tabular}{|c|c|c|}
\hline & $\begin{array}{l}\text { Comportamentos- } \\
\text { queixa }\end{array}$ & $\begin{array}{l}\text { Comportamentos } \\
\text { de melhora }\end{array}$ \\
\hline $\begin{array}{l}\text { Classes } \\
\text { de ordem } \\
\text { inferior }\end{array}$ & $\begin{array}{l}\text { Classes de birra, } \\
\text { oposição e agressão: } \\
\text { choramingar, reclamar, } \\
\text { procrastinar, gritar, que- } \\
\text { brar coisas, recusar-se, } \\
\text { impor e empurrar }\end{array}$ & $\begin{array}{l}\text { Classes de tolerân- } \\
\text { cia, concordância e } \\
\text { assertividade: con- } \\
\text { versar, concordar, } \\
\text { convidar, negociar, } \\
\text { esperar, expressar } \\
\text { sentimentos, dentre } \\
\text { outros }\end{array}$ \\
\hline $\begin{array}{l}\text { Classes } \\
\text { de ordem } \\
\text { superior }\end{array}$ & $\begin{array}{l}\text { Forte controle das } \\
\text { consequências imedia- } \\
\text { tas, atribuição ao outro } \\
\text { como responsável por } \\
\text { solucionar seus proble- } \\
\text { mas }\end{array}$ & $\begin{array}{l}\text { Controle verbal em } \\
\text { geral, autocontrole, } \\
\text { tolerância à aversi- } \\
\text { vidade de situações } \\
\text { e sentimentos, } \\
\text { imitação generali- } \\
\text { zada, papel ativo } \\
\text { como responsável } \\
\text { na resolução de } \\
\text { seus problemas e } \\
\text { empatia }\end{array}$ \\
\hline
\end{tabular}

A maior vantagem da identificação prévia dos comportamentos de melhora e das classes de ordem superior é a possibilidade de se reforçar (do modo como foi discutido), respectivamente, qualquer resposta incipiente que se aproxime do comportamento final e qualquer comportamento que pertença à classe de ordem superior, ainda que não diretamente relacionado à queixa. Você consegue pensar em alguns exemplos de situações na interação terapêutica que poderiam evocar respostas a serem reforçadas? Este seria outro passo importante, pois, com este tipo de previsão, podemos inclusive planejar os contextos mais propícios para a emissão das respostas. Seguem alguns exemplos de contextos e de respostas a serem modeladas nos mesmos. Perceba que muitas das respostas exemplificadas têm correspondência primordialmente com as classes superiores identificadas:

1. Conversas sobre o dia a dia são contextos em que o menino pode relatar e/ou analisar aspectos importantes de sua vida e, nesse sentido, algumas respostas que podem ser modeladas incluiriam: (a) descrições de contingências demonstrando melhoras em sua capacidade de observação do ambiente e auto-observação; (b) descrições de contingências envolvendo consequências a longo prazo (de autocontrole); (c) descrições de tentativas do menino de "parar para pensar" antes de reagir às situações (autocontrole), independente de seu êxito; (d) descrições e expressões emocionais relacionadas à sua capacidade de colocar-se no lugar do outro (empatia); (e) descrições de "sucessos" do menino em interações sociais, mas também (f) descrições de "fracassos" e dos sentimentos associados, que permitiriam à criança entrar em contato com os mesmos e aceitar que nem sempre as coisas dão certo.

2. Conversas sobre o dia a dia são também contextos em que o terapeuta pode modelar respostas relativas ao modo como o cliente interage na sessão: (a) fala com clareza, tom de voz e postura corporal adequadas; (b) há correspondência entre o conteúdo de sua fala e os sentimentos demonstrados (tristeza, alegria, raiva, medo, etc.); (c) ouve atentamente o terapeuta e demonstra interesse por ele; (d) faz perguntas, pedidos, propostas, toma iniciativas, 
mas também (e) aceita ingressar em temas mais desconfortáveis, ainda que demonstre esse desconforto.

3. Treinos do tipo role-play, estruturados ou propostos no meio de conversas, são ocasiões para o terapeuta modelar (e também apresentar modelo de) respostas mais parecidas com aquelas que precisam ser emitidas fora da sessão, o que é especialmente vantajoso para auto-observação e aperfeiçoamento de nuances na topografia das respostas: (a) terapeuta propõe interpretar o papel de alguém significativo (mãe, pai, irmã, professor ou colega) e o cliente reage da maneira que precisaria fazer fora da sessão; (b) terapeuta troca de papel, ficando no papel do cliente e levando-o a interpretar alguém significativo. Nos dois casos, o terapeuta pode liberar consequências voltando esporadicamente a "interpretar a si mesmo" ou então a reagir ainda no papel da outra pessoa, da forma que se imagina que esta reagiria.

4. Atividades em sessão: mais comuns em terapia infantil (Del Prette, 2011), mas também muito úteis na intervenção com adultos, as atividades em sessão são oportunidades de modelar respostas do cliente com menor viés do relato verbal e menor semelhança entre este tipo de interação e as interações baseadas em conversas que ele usualmente tem fora da sessão. Alguns exemplos são: (a) jogos e brincadeiras, em que o menino consiga interagir negociando, propondo, ganhando por mérito e perdendo sem fazer birras; (b) exercícios escolares trazidos para a sessão, em que respostas de autocontrole, resolução de problemas e assertividade podem ser modeladas; (c) exercícios de imaginação ou brincadeiras de fantasia, que tragam, de modo encoberto, estímulos que evoquem as respostas de melhora, emitidas também pelo relato ou demonstração da imaginação.

Em suma, estas e outras intervenções sobre as consequências do responder do cliente são essenciais para instalar e/ou fortalecer um novo repertório que, espera-se, produza mais reforçamento e menos punição em seu ambiente do dia a dia. Isso corresponde à melhora do cliente, que merece uma última análise a ser conduzida. Como você sabe que o cliente "melhorou"? Uma boa maneira de detectar melhoras ao longo do tratamento é pela combinação dos relatos de melhora e dos comportamentos de melhora emitidos na própria interação terapêutica (correspondentes aos comportamentos clinicamente relevantes 2 ou CRB2, de Kohlemberg \& Tsai [2001]). E, dessa forma, uma das maneiras de se organizar tríplices contingências sobre estas mudanças é pela exposição dos dois tipos de indicadores supracitados. Observe alguns exemplos de tríplices contingências de melhora, obtidas por meio do relato do cliente e que incluem interação na escola, com os pais e com a irmã. 


\begin{tabular}{|c|c|c|}
\hline Antecedente & Resposta & Consequência \\
\hline Colega por perto no recreio & Chamar colega para jogar um jogo & Colega aceita $(\mathrm{Sr}+)$ \\
\hline $\begin{array}{l}\text { Colega aceitou jogarem um } \\
\text { jogo }\end{array}$ & $\begin{array}{l}\text { Jogar o jogo sem impor condições } \\
\text { desiguais, aceitando quando perde }\end{array}$ & $\begin{array}{l}\text { Imediata: diversão intrínseca ao jogo e à interação } \\
(\mathrm{Sr}+) \\
\text { Futura: aproximação do colega em outras oportuni- } \\
\text { dades; novas amizades }(\mathrm{Sr}+)\end{array}$ \\
\hline $\begin{array}{l}\text { Pai e menino fazendo compras } \\
\text { no supermercado }\end{array}$ & $\begin{array}{l}\text { Pedir para comprar o sorvete que ele } \\
\text { já havia prometido }\end{array}$ & $\begin{array}{l}\text { Pai fala que não vai comprar nada porque a irmã } \\
\text { está com dor de garganta e vai passar vontade } \\
\text { (Ext) }\end{array}$ \\
\hline $\begin{array}{l}\text { Pai fala que não vai comprar } \\
\text { nada porque a irmã está com } \\
\text { dor de garganta }\end{array}$ & $\begin{array}{l}\text { Falar, com controle do choro, que o } \\
\text { sorvete já era uma promessa }\end{array}$ & $\begin{array}{l}\text { Pai mantém a explicação sobre a irmã (Ext) e orde- } \\
\text { na, ríspido, que ele pare de insistir (Sr-) }\end{array}$ \\
\hline $\begin{array}{l}\text { Pai mantém a explicação sobre } \\
\text { a irmã e ordena, ríspido, que } \\
\text { ele pare de insistir }\end{array}$ & $\begin{array}{l}\text { Calar-se } \\
\text { Ficar triste } \\
\text { Pensar que vai ser forte e não irá } \\
\text { chorar }\end{array}$ & $\begin{array}{l}\text { Interação aversiva é encerrada (Sr-) } \\
\text { A longo prazo: faz o mesmo pedido em outros } \\
\text { momentos, eventualmente obtendo o que se pediu } \\
\left(\mathrm{Sr}_{+}\right)\end{array}$ \\
\hline $\begin{array}{l}\text { Mãe solicita que ele guarde a } \\
\text { louça }\end{array}$ & Obedecer e guardar a louça & Mãe fica de bom humor e satisfeita com ele ( $\mathrm{Sr}+)$ \\
\hline $\begin{array}{l}\text { Mãe de bom humor e satisfeita } \\
\text { com ele }\end{array}$ & Pedir ajuda na tarefa de casa & Mãe o ajuda na tarefa $(\mathrm{Sr}+)$ \\
\hline $\begin{array}{l}\text { Mãe por perto ajudando na } \\
\text { tarefa }\end{array}$ & Faz a tarefa até o fim & $\begin{array}{l}\text { Imediata: tem a tarefa completada, mãe o parabeni- } \\
\text { za, sobra mais tempo para brincar }(\mathrm{Sr}+) \\
\text { Futura: notas melhores, maior aprendizado }(\mathrm{Sr}+)\end{array}$ \\
\hline $\begin{array}{l}\text { Irmã vendo televisão há mais } \\
\text { de uma hora }\end{array}$ & $\begin{array}{l}\text { Pede para a irmã para mudar para o } \\
\text { canal que ele quer }\end{array}$ & Irmã se recusa (Ext) \\
\hline $\begin{array}{l}\text { Irmã se recusa a mudar o } \\
\text { canal de televisão }\end{array}$ & $\begin{array}{l}\text { Fala, enfaticamente, que ela já viu } \\
\text { bastante tempo e é a sua vez }\end{array}$ & Irmã diz que seu programa não acabou (Ext) \\
\hline $\begin{array}{l}\text { Irmã diz que seu programa não } \\
\text { acabou }\end{array}$ & $\begin{array}{l}\text { Pergunta o horário do término e avi- } \\
\text { sa, em tom firme, que nesse horário } \\
\text { ela deverá mudar o canal }\end{array}$ & $\begin{array}{l}\text { Imediata: irmã cumpre o combinado }(\mathrm{Sr}+) \text { e ele ob- } \\
\text { tém a mudança de canal pouco tempo depois }(\mathrm{Sr}+) \\
\text { A longo prazo: maiores possibilidades de realizar } \\
\text { acordos com a irmã, com menos brigas }(\mathrm{Sr}+)\end{array}$ \\
\hline
\end{tabular}


Pela análise de contingências de melhora, percebe-se que as novas respostas do menino passaram a produzir diversos reforços positivos (atenção, ajuda, ganhos específicos, aprendizado), redução da punição ou extinção e também benefícios a longo prazo, que também manteriam a continuidade desse padrão de interação. Assim como o ambiente outrora modelou equivocadamente as respostas-queixa, agora se espera que as mudanças sejam sustentadas pelas pessoas significativas de sua vida, auxiliando na manutenção e no refinamento das habilidades aprendidas. A mudança nas consequências também modifica, indiretamente, a função do contexto antecedente que, agora, sinaliza a ocasião para outras respostas e para mais reforço positivo do que punição. Quando os antecedentes deixam de funcionar como pré-aversivos e passam a ser sinalizadores de reforço, mais e mais torna-se possível a aprendizagem de comportamentos novos. $\mathrm{O}$ menino ativamente mudou as contingências de sua vida e esse é um dos principais aspectos que, eventualmente, alguém poderia descrever como "autoestima alta": uma complexa rede de contingências sociais positivamente reforçadoras!

\section{Considerações Finais}

Este artigo procurou focar o ensino da seleção de comportamentos-alvo, a qual contempla essencialmente as habilidades de observar, descrever e sistematizar a tríplice contingência e sua interpretação, assim como de efetuar a previsão de intervenções sobre as consequências, a despeito da escolha por técnicas específicas. Outras questões não abordadas, principalmente quanto ao foco nos antecedentes, também merecem a atenção do analista em formação. É importante que elas sejam analisadas e descritas na forma de material didático, auxiliando o treinamento do analista em formação. Estas questões incluem aspectos como o controle de estímulos, o manejo do comportamento verbal e o papel das operações estabelecedoras. Caso você queira continuar exercitando sua capacidade analítica, para além do espaço deste artigo, será interessante perguntar para si mesmo: o que teria acontecido com o menino se não houvesse mudança no seu padrão de interação social? Como ele seria, quando adulto? E como ele poderá ser, com a continuidade das mudanças alcançadas? Ao responder estas per- guntas, não podemos ser deterministas e incorrer no erro de supor que somente a terapia seria capaz de alterar o curso da história dos indivíduos, ou que uma criança com tais problemas estaria automaticamente fadada a ser um adulto com questões ainda mais graves. É exatamente pela sensibilidade às consequências e pela plasticidade do comportamento que alterações podem ocorrer em diversas direções ao longo da vida. Por outro lado, é importante considerar que a terapia é uma maneira de se alterar contingências de modo planejado e a partir de ferramentas que o analista possui, advindas de uma compreensão científica do comportamento.

\section{Referências}

Ayllon, T., \& Azrin, N. H. (1968). The token economy: A motivational system for therapy and rehabilitation. New York: Appleton-Century-Crofts.

Carrara, K. (2005). Behaviorismo radical: Crítica e metacrítica (2a ed.). São Paulo: UNESP.

Catania, A. C. (1999). Aprendizagem: Comportamento, linguagem e cognição ( $4^{\mathrm{a}}$ ed.; D. G. Souza et al., Trads.). Porto Alegre: Artmed.

Del Prette, G., \& Almeida, T. A. C. (2011). O uso de técnicas na clínica analítico-comportamental. Em: N. B. Borges \& F. A. Cassas (Orgs), Clínica analítico-comportamental: Aspectos teóricos e práticos (pp. 147-160). Porto Alegre: Artmed.

Del Prette, G. (2011). Objetivos analítico-comportamentais e estratégias de intervenção nas interações com a criança em sessões de duas renomadas terapeutas infantis (Tese de doutorado). Universidade de São Paulo, São Paulo, SP.

Ferster, C. B. (1967). Arbitrary and natural reinforcement. The Psychological Record, 17, 341-347.

Garfield, S. L. (1980). Psychotherapy: An ecletic approach. New York: Wiley.

Hill, C. E. (1999). Open questions and probes. Em C. E. Hill \& K. M. O’Brien (Orgs.), Helping skills: Facilitating, exploration, insight and action (pp. 117-128). Washington: American Psychological Association.

Horcones (1992). Natural reinforcement: A way to improve education. Journal of Applied Behavior Analysis, 25, 71-75.

Kazdin, A. E. (1988). Child psychotherapy: Developing and identifying effective treatments. New York: Pergamon Press. 
Kazdin, A. E., \& Weisz, J. R. (2003). Evidence-based psychotherapies for children and adolescents. New York: Guilford Press.

Kohlenberg, R. J., \& Tsai, M. (2001). Psicoterapia analítica funcional: Criando relações terapêuticas intensas e curativas (R. R. Kerbauy et al., Trad.). Santo André: ESETec.

Lattal, K. A. (2005). Ciência, tecnologia e análise do comportamento. Em J. Abreu-Rodrigues \& M. R. Ribeiro (Orgs.), Análise do comportamento: Pesquisa, teoria e aplicação (pp. 15-26). Porto Alegre: Artmed.

Meyer, S. B., Del Prette, G., Zamignani, D. R., Banaco, R. A., Neno, S., \& Tourinho, E. Z. (2010). Análise do comportamento e terapia analítico-comportamental. Em E. Z. Tourinho \& S. V. Luna (Orgs.), Análise do comportamento: Investigações históricas, conceituais e aplicadas (pp. 153-174). São Paulo: Roca.

Meyer, S. B. (2000). Mudamos, em terapia verbal, o controle de estímulos? Acta Comportamentalia, $8(2), 215-225$.

Santos, J. A., \& de Rose, J. C. (1999). A importância do reforço natural na formação do hábito de leitura. Revista Olhar, 1(2), 1-6.

Sidman, M. (2001). Coerção e suas implicações (M. A. Andery e T. M. Sério, Trads.). Campinas: Editorial Psy.

Skinner, B. F. (1970). Ciência e comportamento humano (J. C. Todorov e R. Azzi, Trads.). Brasília: Editora Universidade de Brasília. (Trabalho original publicado em 1953)

Skinner, B. F. (1938). The behavior of organisms. New York: Appleton-Century.

Skinner, B. F. (1992). Verbal behavior. Acton: Copley. (Trabalho original publicado em 1957)

Sturmey, P. (1996). Functional analysis in clinical psychology. Chichester: John Wiley \& Sons.

Tourinho, E. Z. (1999). Estudos conceituais na análise do comportamento. Temas em Psicologia, 7(3), 213-222.

Tsai, M., Kohlenberg, R. J., Kanter, J. K., Kohlenberg, B., Follette, W., \& Callaghan, G. M. (2009). A guide to functional analytic psychotherapy: Awareness, courage, love and behaviorism. New York: Springer.
Vollmer, T. R., \& Iwata, B. A. (1992). Differential reinforcement as treatment for behavior disorders: Procedural and functional variations. Research in Developmental Disabilities, 13(4), 393-417.

\section{Observações}

1 As funções presumidas dos estímulos consequentes estão sendo representadas com as seguintes notações: $\left(\mathrm{Sr}^{+}\right)$produção de estímulo reforçador positivo; (Sr-) produção de estímulo reforçador negativo; ( $\mathrm{Sr}+$ ) remoção de estímulo reforçador positivo; (Sr=) remoção de estímulo reforçador negativo e (Ext) extinção.

\section{Informações do artigo}

\section{História do artigo}

Data de submissão em: 10/08/2011

Primeira decisão editorial em: 30/08/2011

Aceito para publicação em: 19/10/2011 